\title{
Igualdad y libertad laborales para la mujer
}

\author{
Por Javier GOROSOUIETA
}

\section{MENTALIDAD TRADICIONAL Y MENTALIDAD MODERNA}

Al hablar sobre el trabajo de la mujer se topa, en el punto de partida, con el eterno interrogante: ¿Dónde está el puesto de la mujer, en el hogar o en la empresa?

De la jerarquía de valores implícita en nuestro Fuero del Trabajo brotó la prioridad por la primera alternativa. Declara, en efecto, en su artículo II, 1 , que la ley "libertará a la mujer casada del taller y de la fábrica”.

Más adelante en el tiempo, en 1961, una ley importante sobre los derechos políticos, profesionales y de trabajo de la mujer en España, encarna una mentalidad nueva, pero sorteando con habilidad el escollo de la anterior declaración del Fuero del Trabajo. Reza así el preámbulo de la ley: "Sigue siendo nor. ma programática del Estado español, anunciada por la declaración segunda del Fuero del Trabajo, la de "libertar a la mujer casada del taller y de la fábrica", pero ni esta norma veda el acceso de la mujer a la multiplicidad-por lo demás crecientede ocupaciones no manuales, ni en cuanto a las manuales puede ni debe conseguirse por normas discriminatorias y prohibitivas, que más perjuicios que beneficios causan, sino por la elevación general de las rentas de trabajo, reales y no nominales, del marido, que, en conjunción con otros programas, señaladamente el de la vivienda, ... permitan al cabeza de familia el mantenimiento con lo procedente de su solo trabajo y esfuerzo de un nivel de vida digno para su familia" (1).

La sutileza es evidente, pero creemos, sin embargo, que apunta en el mejor de los sentidos. Oígamos, sin embargo, a

(1) Ley de 22 de fullo de 1961, sobre los derechos políticos, profesionales y de trabajo de la mujer. 
título de ejemplo, la siguiente conclusión de la Conferencia Internacional de la Familia, celebrada en Madrid ese mismo año de 1961 y en el mismo mes de aprobación de la citada ley: "El salario del cabeza de familia debe ser suficiente para permitirle atender a las necesidades de un hogar normal y en relación con la evolución social de cada país. Es necesario conseguir un sistema de prestaciones familiares que suprima la estrechez económica que obliga a muchas madres a dedicarse a un trabajo remuneradorn (2). (EI subrayado es nuestro.)

Pero, a pesar de las leyes, la mentalidad tradicional ( "la mujer casada, en casa y la pierna quebrada", que dice el refrán) aflora cuando menos se espera, de forma abierta o solapada en los más distanciados niveles sociales. Como muestra de talante tradicional bajo capa progresista, podríamos citar la la siguiente manifestación del Libro Blanco "La Educación en España": "... la labor de educación de los hijos, que se lleva a cabo en el seno del hogar, y que escapa a toda valoración, es un factor frecuentemente olvidado y que en la actualidad empieza a ser tenido muy en cuenta en los países con altos niveles de renta, por su trascendencia social e incluso económica. En efecto, en la medida en que la educación es considerada como la palanca fundamental del progreso social y del desarrollo económico, sería una contradicción subestimar la inapreciable aportación que la mujer (preferiblemente una mujer culturalmente elevada) puede efectuar en este aspecto tan crucial como es la educación de los niños, y que puede afirmarse, aun desde el punto de vista estrictamente económico, no digamos desde el punto de vista social, es en muchos casos notablemente superior a la aportación al producto social que la mujer pudiera efectuar en su incorporación a las unidades económicas de pro. ducción" (3).

Como expresión directa del criterio clásico, acudiré a una reciente encuesta realizada entre obreros españoles de la construcción. Se entrevista a 789 trabajadores de diferentes obras. A la primera pregunta: "En general, si no hubiera necesidad económica, ies usted partidario de que la mujer trabaje fuera del hogar?", responde "no" el 83 por 100 , y sólo el 17 por 100 , "Sí". $Y$ ulteriores datos del mismo sondeo confirman que a mayor número de hijos son menos partidarios del trabajo de la mujer fuera de casa, y que a menor cultura sucede lo mismo (4).

Sin embargo, se está superando esta actitud tradicional,

(2) Conferencia Internacional de la Familia: El trabajo de la madre de familia. Ediciones de la Comisión Permanente de los Congresos de la Familia Española. Madrìd, 1962, pág. 135.

(3) Ministerio de Educación y Ciencia: La educación en España. Madrid, 1969, pág. 123.

(4) Encuesta del Departamento de Investigación Sociológica (D. 1. S.) sobre los obreros de la construcción del Area Metropolitana de Madrid en 1974, págs. 175 y sigs. Ejemplar multicopiado. 
como lo demuestra, v. gr., el cuadro número 1 , de respuestas a otra amplia encuesta entre las amas de casa españolas (5):

GUADRO NUM. 1

Tanto por ciento que dicen que la mujer debe trabajar, según su estado

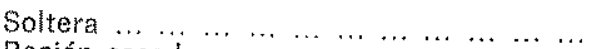

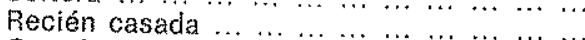

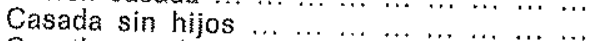

Casada con hijos pequeños...

Casada con hijos mayores

\begin{tabular}{|c|c|c|}
\hline Rusral & Urbano & $\begin{array}{l}\text { Metropo } \\
\text { litano }\end{array}$ \\
\hline 87 & 92 & 96 \\
\hline 52 & 50 & 65 \\
\hline 64 & 66 & 75 \\
\hline 17 & 15 & 15 \\
\hline 40 & 35 & 47 \\
\hline
\end{tabular}

Como se puede observar en el cuadro, el proceso progresivo de urbanización está alterando las posturas tradicionales. En conjunto es mucho más liberal con el trabajo de la mujer el ama de casa metropolitana que la urbana, y estas dos, mucho más que la rural.

En definitiva, la mujer moderna quiere no verse obligada por necesidad al trabajo fuera de casa, pero sí tener libertad para emprenderlo cuando la interese. $Y$ esto último, además, en igualdad de condiciones con el varón.

\section{"A TRABAJO IGUAL, SALARIO IGUAL", EN LA LETRA DE LA LEY}

Así, en la Ley española antes citada, de 22 de julio de 1961 , se establece que "la Ley reconoce a la mujer los mismos derechos que al varón para el ejercicio de toda clase de actividades políticas, profesionales y de trabajo, sin más limitaciones que las establecidas en la presente Ley" (art. 1.0); que "la mujer podrá celebrar toda clase de contratos de trabajo" (artículo $4.0^{\circ}$ ); que "en las Reglamentaciones de Trabajo, convenios colectivos y reglamentos de empresa no se hará discriminación alguna en perjuicio del sexo o del estado civil, aunque este último se altere en el curso de la relación laboral" (ib.); que "las disposiciones laborales reconocerán el principio de igual. dad de retribución de los trabajos de valor igual" (ib).

Este famoso principio, "a trabajo igual, salario igual", comenzó a ser considerado en 1919 en la constitución de la Orga-

(5) Informe FOESSA 1970. Edic. Euramérica. Madrild, 1970, pág. 1063. 
nización Internacional del Trabajo (O.I.T.); fue reasumido por la misma Organización en 1946; incluido en la Declaración de las Naciones Unidas sobre los derechos humanos, en 1948; explicitado en la convención número 100 de la O.I.T., en 1951; ratificado en el artículo 119 del Tratado de Roma, creador del Mercado Común Europeo; aprobado en 1966 por la Comisión de la Condición de la Mujer, en el seno de las Naciones Unidas: igualdad en formación profesional y en el trabajo, igualdad de remuneración; la maternidad no es factor de discriminación; garantía de retorno al empleo después de la maternidad.

El mismo principio se repite de una u otra forma hoy en la legislación de todos los países desarrollados y en bastantes otros de la periferia económica mundial. Ha sido una conquista más de la mujer, y una conquista justa. Escribía Juan XXIII en su encíclica "Pacem in Terris": "Es un hecho evidente la presencia de la mujer en la vida pública. Este fenómeno se registra con mayor rapidez en los pueblos que profesan la fe cristiana, y con más lentitud, pero siempre en gran escala, en paises de tradición y civilización distintas. La mujer ha adquirido una conciencia cada día más clara de su propia dignidad humana. Por ello, no tolera se la trate como cosa inanimada o mero instrumento; exige, por el contrario, que tanto en el ámbito de la vida doméstica como en el de la vida pública, se le reconozcan los derechos y obligaciones propios de la persona humana".

\section{LA ATRACION DE LA FABRICA}

Como veremos más adelante, la mujer ha respondido, con su acceso efectivo y creciente a la vida socioeconómica, a ese reconocimiento teórico y legal de su libertad y de su dignidad. $Y$ esto no solamente por motivaciones económicas, que son, es verdad, como también veremos, las más frecuentes. Es impresionante, p. ej.. leer a esa gran escritora francesa, tornera de oficio, que es Michèle Aumont, cuando, después de describir la penosidad del trabajo de la mujer en muchas fábricas francesas, confiesa: "La mujer se convierte así, cada vez más, en la compañera del hombre en todas sus actividades. No aspira a economizar su esfuerzo en la fábrica (iy qué esfuerzo tan penoso, muchas veces!), ni los riesgos que corren su salud, su feminidad y su vida de mañana. ¿Por qué? Porque la vida de la fábrica no es solamente una vida dura. Tiene también su belleza, sus particularidades e incluso su grandeza. Nosotras amamos nuestra vida y amamos la fábrica, aunque queramos transformar una y otra, aunque estimemos que trabajamos demasiado y demasiado duramente, en condiciones inhumanas y anormales. ¿Por qué, pues, esta atracción? Porque la fábrica tiene un doble aspecto. 
"La fábrica es el ruido, las órdenes, la estricta disciplina, el cronómetro, el rendimiento, los reproches y, a veces, la falta de consideración. Pero la fábrica es también un gran corazón que late y que amamos sentir latir. El universo de la producción, máquinas, cadenas de montaje y talleres, nos hiere algunas veces hasta el agotamiento o el accidente. Pero el universo de la producción es un vasto dominio, bello, aunque de una belleza particular, y un gran cuerpo que tiene algo de vivo y alucinante, donde queremos estar presentes, cooperar y desempeñar nuestro papel. Cadenas y equipos de trabajo piden demasiado de nosotras; pero cadenas y equipos no son por sí mismos hostiles e inhumanos. Allí nosotras vivimos plenamente la solidaridad de grupo, que es como el alma de nuestra existencia. Quisiéramos que esta solidaridad guiase, inspirase y animase todas las relaciones y los contactos de fábrica; entonces serían verdaderamente humanas y hasta magníficas. Nuestras jornadas de fábrica están todas marcadas por este doble carácter, penoso e inhumano, por un lado; pero, por otro, también por una cooperación estrecha, la camaradería y la cálida solidaridad, que fortifican y son tan hermosas" (6).

Con peor estilo, pero con parecida intuición, otras declaran que el aislamiento social, la soledad y el desequilibrio emocional que esto provoca en el ama de casa son motivos que impulsan a las mujeres casadas a buscar ocupación fuera de sus hogares; que en el medio de trabajo, como en todo medio humano, pueden surgir conflictos y rivalidades, pero que, no obstante, el conjunto es atrayente por el clima de camaradería y solidaridad que en él se aprecia a menudo.

\section{PREDOMINIO DE LAS MOTIVACIONES ECONOMICAS}

De todas formas y como arriba indicamos, son las motivaciones económicas las que con mayor frecuencia impelen a la mujer a incorporarse a la vida económicamente activa. Veamos el resultado de algunos sondeos que lo confirman. ciones:

E. Perroy obtuvo en Francia la siguiente gama de motiva

1. En el medio obrero trabajan:

- Para mejorar el presupuesto familiar, el 95 por 100 de las mujeres económicamente activas.

Para permitir a los hijos el proseguir los estudios, el 79 por 100.

(6) Michèle Aumont: "Les femmes en usine: une expérience personnellè, en Revue Internationale du Travail, vol. 74 , núm. 4, págs. 393 y sigs. 
- Para obtener una pensión para la vejez, el 28 por 100.

- Para efectuar compras a plazos, el 23 por 100.

- Por gusto e interés en el oficio, el 15 por 100.

2. En la clase media:

- Para mejorar el presupuesto familiar, el 95 por 100.

- Para permitir a los hijos proseguir estudios, el 77 por 100.

- Por afición al oficio, el 49 por 100.

- Porque se aburrían en casa, el 40 por 100.

3. En la clase acomodada:

- Para mejorar el presupuesto familiar, el 95 por 100.

- Por afición al oficio, el 58 por 100.

- Porque se aburren en casa, el 50 por 100.

- Para ser independientes, el 49 por 100 (7).

Como vemos en esta encuesta, las motivaciones económicas guardan su vigor a todos los niveles, pero, al mismo tiempo, en los medios económicamente más desahogados las razones extraeconómicas van adquiriendo fuerza progresiva.

En España y en la encuesta antes aludida entre los obreros de la construcción, aparece que el porcentaje de mujeres que trabajan fuera es tanto más elevado cuanto mayor es el número de hijos y más bajo el sueldo del marido; es decir, que lo hacen sobre todo por necesidad. De las que trabajan, el 55 por 100 son esposas de obreros con sueldo base mínimo y sólo el 11 por 100 lo son de obreros con sueldo superior a las 16.000 pese. tas. En cuanto al número de hijos, las que tienen de 3 a 6 hijos suman el 32 por 100 del colectivo que trabaja, frente al 5 por 100 sin hijos, 14 por 100 con un hijo y 8 por 100 con dos $(8)$. La conclusión no es apodíctica, por la relativa pequeñez de la muestra-789 trabajadores-, pero creemos apunta en el buen sentido y que resulta, por lo tanto, un indicador válido.

De otra encuesta española mucho más amplia obtenemos, por otra parte, los mismos resultados (Cuadro núm. 2) (9):

(7) Citado por Noemi Yunes Zajur en Revista de la Opinión Pública, número 30, págs. 197 y sigs.

(8) D.I.S., o. c., págs. 182 y sigs.

(9) Fundación FOESSA, O. c., pág. 1088. 
CUADRO NUM 2

Razones por las que la entrevistada trabaja, por clase social subjetiva (en tantos por ciento)

\begin{tabular}{|c|c|c|c|c|c|c|}
\hline Razones & $\begin{array}{c}\text { Alta y } \\
\text { media } \\
\text { alta }\end{array}$ & Media & $\begin{array}{l}\text { Mecia } \\
\text { Media } \\
\text { baja }\end{array}$ & Obrera & Pobre & Total \\
\hline Para ayudar a su casa & 35 & 55 & 77 & 72 & 77 & 68 \\
\hline Para ayudar al marido .... .... & 8 & 15 & 11 & 16 & 10 & 13 \\
\hline $\begin{array}{l}\text { Para hacer algo util ........... } \\
\text { Para pagar estudios de los }\end{array}$ & 18 & 13 & 3 & 5 & 9 & 10 \\
\hline 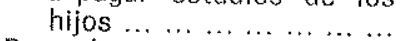 & 3 & 2 & 2 & 1 & 1 & \\
\hline 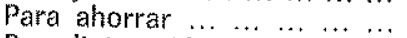 & 5 & 4 & 1 & 2 & 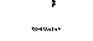 & 2 \\
\hline 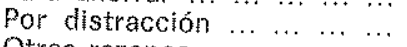 & 20 & 5 & 1 & 2 & - & 3 \\
\hline Otras razones $\ldots \ldots \ldots \ldots \ldots$ & 15 & 6 & 5 & 2 & 3 & 4 \\
\hline
\end{tabular}

Aparece claro cómo los motivos extraeconómicos ("por hacer algo útil", "por distracciónn) brillan por su ausencia en las clases subjetivas pobres, a partir de la clase media baja inclusive.

No queremos abrumar al lector con más investigaciones empíricas de otros países, que abundan todas en los mismos resultados.

\section{"A TRABAJO IGUAL, SALARIO IGUAL", EN LA PRACTICA}

Como indicamos antes, desde el punto de vista de la liberación de la mujer sería deseable que no tuvieran que trabajar fuera de casa por necesidad. Pero, puesto que la necesidad existe, habría que lograr, al menos, la igualdad laboral con el varón. Ya vimos que esta igualdad está reconocida en la legislación de numerosos países y en las declaraciones y convenios de las más importantes organizaciones político-sociales a nivel internacional. Mas una cosa son las declaraciones de la ley y otra muy distinta, a menudo, las realidades sociológicas. A este último nivel la discriminación continúa. Este hecho aflora de una $u$ otra forma en todos los países; pero limitémonos ahora a nuestro caso en España.

"En España, al confrontar las tarifas de salarios de varones y mujeres, particularmente cuando responden a la misma categoría profesional-y no a labores específicamente femeninas-. se obtienen proporciones muy variables, desde un jornal femenino que representa el 70 ó el 75 por 100 del masculino, hasta el 90 por 100; sin que falten, es verdad, diferencias más pequeñas. Acaso pudiera establecerse una tendencia a establecerse aquél en un 70 u 80 por 100 del segundo. Pero, en con- 
creto, algunas Reglamentaciones, como las de la industria del arroz, calzado, manipulado y exportación de frutos secos, minas de potasio, azufre, etc., cueros repujados, marroquinería y similares, prescriben taxativamente que cuando no se indique una actividad como específicamente femenina, al ser desarrolladas por operarias, percibirán éstas el 80 por 100 del salario masculino. En cambio, en alguna otra, como la de guantes de piel, se preceptúa que el personal femenino ocupado en actividades típicamente masculinas percibirán el mismo haber que los varones. La reglamentación de confección, vestido y tocado (grupo de complemento de vestido), atribuye a las mujeres el 80 por 100 del salario masculino, salvo los peones, en que la retribución será igual. Añádase, como norma de validez universal en el mundo del trabajo español, que los servicios de carácter administrativo y técnico (cuando son accesibles a las mujeres) no distingue los sexos a efectos remunerativos."

Así describe Antonio Perpiñá la panorámica española en cuanto a retribución del trabajo de la mujer en 1962 (10). E) paréntesis "cuando son accesibles a las mujeres" se explica por lo siguiente: la repetidamente citada Ley de 22 de julio de 1961, a pesar de estar regida por un criterio no discriminatorio y ser esa su intención y razón de ser, excluye a la mujer de determinadas funciones, como la de "administración de jus ticia, en los cargos de Magistrados, Jueces y Fiscales, salvo en las jurisdicciones Tutelar de Menores y Laboral" (art. 3..$^{\circ}$, el ejercicio de las armas y las funciones no sanitarias de la Marina mercante. Bien es verdad que, años más tarde, una Ley del día de los Inocentes (28 de diciembre) de 1966 estableció el acceso de la mujer a los cargos de Magistrado, Jueces y Fiscales de Administración de Justicia, avanzando, de esta forma, notablemente, sobre la de 1961.

En 1965 constataba la misma realidad del salario femenino discriminatorio José Jané Solá, en su tesis doctoral sobre "El problema de los salarios en España". En veinte empresas analizadas de Barcelona, La Coruña, Madrid, Valencia y Zaragoza, cuatro de ellas de más de 1.000 obreros, constata unas "aberturas" salariales que van desde 1,01 hasta 3,30. Es decir, que, en esta última empresa, por ejemplo, por cada peseta que gana una obrera de máxima calificación profesional, el obrero de la misma categoría gana 3,20. Concluye Jané Solá: "Parece ser que, en las unidades productivas donde se requiere mano de obra altamente cualificada, y en el comercio, las diferencias debidas al sexo alcanzan su máximo valor. De todos modos, es patente

(10) Antonio Perpiñá Rodríguez: La estructura de los salarios en España. Estudio sobre el salario diferencial. Ed. Consejo Superior de Investigaciones Científicas. Madrid, 1962, pág. 44. 


\section{que el trabajo femenino se encuentra minuspagado con respecto al masculino» (11).}

Que esta situación no ha desaparecido en años posteriores nos los muestra, v. gr., el Anuario Estadístico de España correspondiente a 1974. De él recogemos los tres cuadros núms. 3, 4 y 5 , que se refieren a los datos de 1973 (12).

\section{CUADRO NUM. 3}

Retribución horaria en pesetas

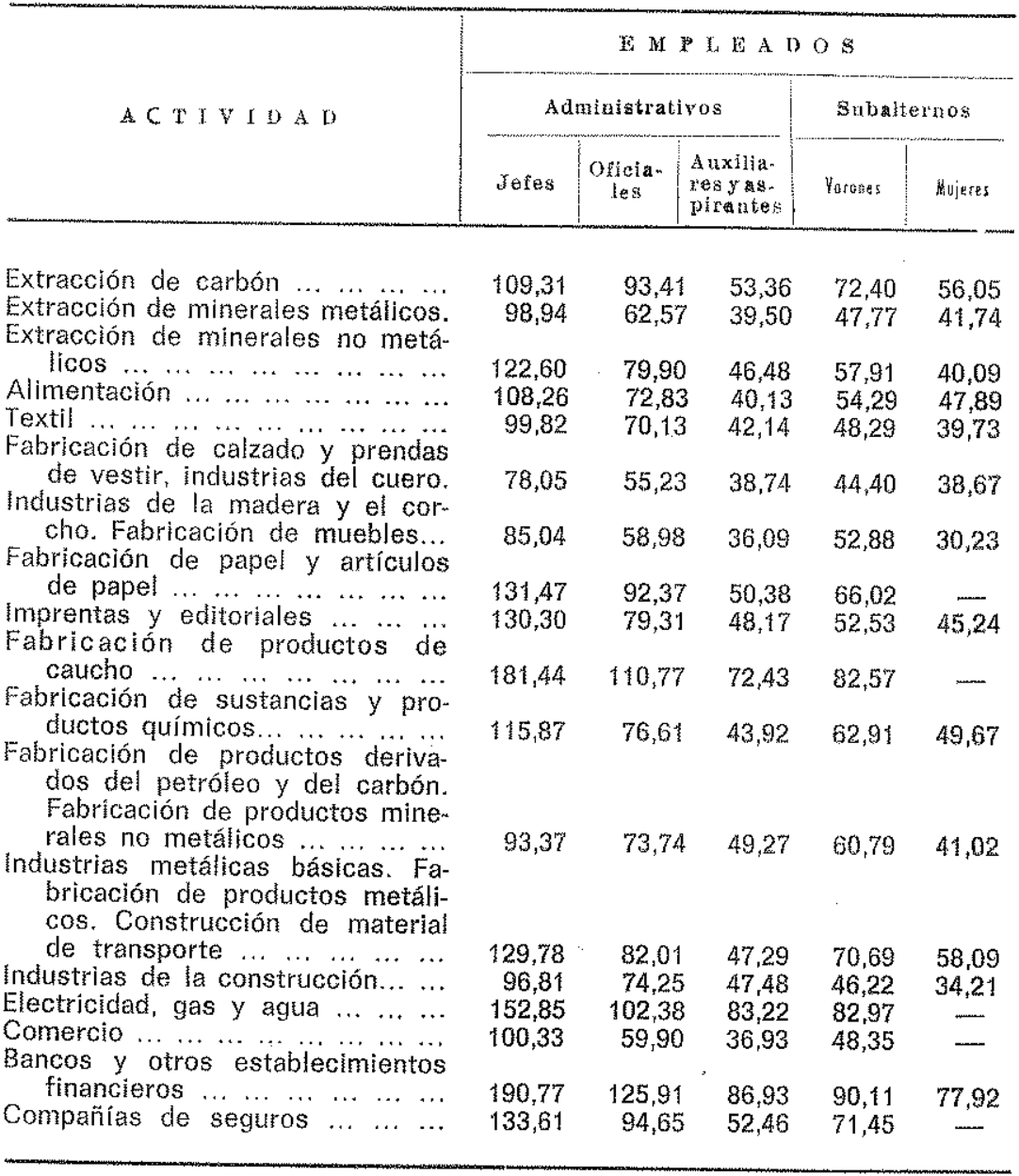

(11) José Jané Solá: El problema de los salarios en España Olkos-tau, Sociedad Anónima de Ediciones. Barcelona, 1969, pág. 142.

(12) Anuario Estadístico de España, 1974, págs. 272-274. 
CUADRO NUM. 4

Retribución horaria en pesetas

\begin{tabular}{|c|c|c|c|c|c|c|}
\hline \multirow{3}{*}{ ACTIVIDAD } & \multicolumn{6}{|c|}{. OPERARIOS } \\
\hline & \multicolumn{2}{|c|}{$\begin{array}{l}\text { Jefes de equipo } \\
\text { y ofieiales } \\
\text { de primera }\end{array}$} & \multicolumn{2}{|c|}{$\begin{array}{l}\text { Oficiales de } \\
\text { segunda } \\
y \text { tereera }\end{array}$} & \multicolumn{2}{|c|}{$\begin{array}{l}\text { Peotres especia- } \\
\text { lizados o espre- } \\
\text { cialistas }\end{array}$} \\
\hline & Varones & Mujeres & Varones & Mujeres & Yaroaes & Mujeres \\
\hline $\begin{array}{l}\text { Extracción de carbón ....... } \\
\text { Extracción de minerales me- }\end{array}$ & 143,43 & - & 88,75 & - & 94,53 & - \\
\hline $\begin{array}{l}\text { tálicos ...................... } \\
\text { Extracción de minerales no }\end{array}$ & 64,85 & - & 59,78 & - & 54,92 & - \\
\hline metálicos $\ldots \ldots \ldots \ldots \ldots$ & 66,41 & $\underline{-}$ & 70,34 & - & 56,50 & - \\
\hline Alimentación... $\ldots \ldots \ldots c c c c$ & 63,87 & 38,49 & 53,42 & 36,99 & 50,44 & 36,64 \\
\hline $\begin{array}{l}\text { Textil ... } \\
\text { Fabricacion de calzado y } \\
\text { prendas de vestir. Indus. }\end{array}$ & 64,59 & 46,44 & 50,91 & 39,51 & 52,45 & 34,02 \\
\hline $\begin{array}{l}\text { tria del cuero ............. } \\
\text { Industria de la madera y } \\
\text { el corcho. Fabricación de }\end{array}$ & 50,17 & 41,24 & 40,82 & 33,50 & 39,45 & 29,44 \\
\hline $\begin{array}{c}\text { muebles } \ldots . . . . . \\
\text { Fabricación de papel y }\end{array}$ & 45,39 & 38,28 & 39,58 & 33,20 & 34,53 & 28,71 \\
\hline tículos de papel .......... & 72,08 & 48,97 & 65,20 & 42,68 & 53,02 & 43,79 \\
\hline $\begin{array}{l}\text { Imprentas y editoriales ... } \\
\text { Fabricación de productos }\end{array}$ & 78,34 & 62,94 & 58,18 & 48,33 & 57,31 & 41,52 \\
\hline $\begin{array}{l}\text { de caucho .............. } \\
\text { Fabricación de sustancias y }\end{array}$ & 98,07 & 79,37 & 66,17 & 52,92 & 88,44 & 59,24 \\
\hline $\begin{array}{l}\text { productos químicos ....... } \\
\text { Fabricación de productos } \\
\text { derivados del petróleo y } \\
\text { del carbón. Fabricación } \\
\text { de productos minerales }\end{array}$ & 67,61 & 45,88 & 63,21 & 34,21 & 59,56 & 51,80 \\
\hline $\begin{array}{l}\text { no metálicos ......... } \\
\text { Industrias metálicas b ás ì } \\
\text { cas. Fabricación de pro- } \\
\text { ductos metálicos. Cons- } \\
\text { trucción de material de }\end{array}$ & 62,98 & 53,97 & 57,13 & 43,99 & 51,65 & 39,30 \\
\hline $\begin{array}{l}\text { transporte } \\
\text { industrias de la }\end{array}$ & 72,59 & - & 65,10 & - & 71,86 & 56,76 \\
\hline ción $\ldots \ldots \ldots \ldots \ldots \ldots$ & 54,42 & - & 46,41 & - & 43,29 & - \\
\hline $\begin{array}{l}\text { Electricidad, gas y agua ... } \\
\text { Comercio }\end{array}$ & 90,72 & - & 76,44 & - & 66,47 & - \\
\hline $\begin{array}{l}\text { Comercio } \ldots \ldots \ldots \ldots \ldots \ldots \\
\text { Bancos y otros estableci. }\end{array}$ & 54,00 & - & 46,15 & 35,71 & 38,79 & $\ldots$ \\
\hline $\begin{array}{l}\text { mientos financieros... } \\
\text { Compañias de seguros }\end{array}$ & 118,44 & - & 114,55 & - & 96,46 & - \\
\hline & 67,80 & - & . & - & 60,03 & - \\
\hline
\end{tabular}


CUADRO NUM 5

Retribución horaria en pesetas

\begin{tabular}{|c|c|c|c|c|c|}
\hline \multirow{3}{*}{$A C T I V I D A D$} & \multicolumn{4}{|c|}{ OPERARIOS } & \multirow{3}{*}{$\begin{array}{l}\text { Remune } \\
\text { racion } \\
\text { media } \\
\text { por } \\
\text { actividad }\end{array}$} \\
\hline & \multicolumn{2}{|c|}{ Poones } & \multicolumn{2}{|c|}{$\begin{array}{l}\text { Ayudantes } \\
\text { y pinches }\end{array}$} & \\
\hline & Varonos & Mujeres & Varones & Mujeres & \\
\hline $\begin{array}{l}\text { Extracción de carbón } \ldots \ldots \ldots \ldots \\
\text { Extracción de minerales meta. }\end{array}$ & 78,71 & - & 39,90 & - & 112,44 \\
\hline $\begin{array}{l}\text { licos } \ldots \ldots \ldots \ldots \ldots \ldots \ldots \\
\text { Extracción de minerales no me }\end{array}$ & 46,73 & 42,60 & 19,53 & $\cdots$ & 57,57 \\
\hline $\begin{array}{rlllllll}\text { tálicos } & \ldots & \ldots & \ldots & \ldots & \ldots & \ldots & \ldots\end{array}$ & 48,69 & - & 34,94 & $\ldots$ & 69,21 \\
\hline $\begin{array}{l}\text { Alimentación... } \\
\text { Textil }\end{array}$ & $\begin{array}{l}39,39 \\
30,90\end{array}$ & 27,39 & 22,23 & 21,08 & 49,44 \\
\hline $\begin{array}{l}\text { Fabricacion de calzado y pren } \\
\text { das de vestir, industria del }\end{array}$ & 39,80 & 32,62 & 25,73 & 22,28 & 50,06 \\
\hline $\begin{array}{c}\text { cuero } \ldots \ldots \ldots \ldots \ldots \\
\text { Industria de la madera y el cor- }\end{array}$ & 37,24 & 31,46 & 19,12 & 17,44 & 36,97 \\
\hline $\begin{array}{l}\text { cho. Fabricación de muebles. } \\
\text { Fabricación de papel y articu }\end{array}$ & 33,67 & 30,54 & 19,19 & 19,57 & 39,43 \\
\hline los de papel $\ldots \ldots \ldots \ldots$ & 47,38 & 38,60 & 27,38 & 23,54 & 64,27 \\
\hline $\begin{array}{l}\text { Imprentas y editoriales... ... ... } \\
\text { Fabricación de productos de }\end{array}$ & 41,91 & 41,53 & 28,37 & 22,23 & 64,43 \\
\hline $\begin{array}{l}\text { caucho } \ldots \ldots \ldots \text {.................... } \\
\text { Fabricacion de sustancias y pro- }\end{array}$ & 63,38 & 31,17 & 30,89 & 22,42 & 86,32 \\
\hline $\begin{array}{l}\text { ductos químicos ............ } \\
\text { Fabricación de productos deri- } \\
\text { vados del petróleo y el car- } \\
\text { bón. Fabricación de produc- } \\
\text { tos minerales }\end{array}$ & 47,11 & 41,26 & 27,11 & 18,87 & 65,63 \\
\hline $\begin{array}{l}\text { tos minerales no metálicos. } \\
\text { Industrias metálicas básicas. } \\
\text { Fabricación de productos me- } \\
\text { tálicos. Construcción de ma- } \\
\text { terial de transportes }\end{array}$ & 39,08 & 32,17 & 21,24 & 25,47 & 55,17 \\
\hline $\begin{array}{l}\text { terial de transportes ......... } \\
\text { Industrias de la construcción... }\end{array}$ & 48,45 & 43,14 & 21,06 & 29,26 & 72,28 \\
\hline $\begin{array}{l}\text { ndustrias de la construcción... } \\
\text { Electricidad gas y agua ........ }\end{array}$ & $\begin{array}{l}37,28 \\
57,64\end{array}$ & 35,71 & $\begin{array}{l}23,61 \\
33,28\end{array}$ & $=$ & 48,51 \\
\hline 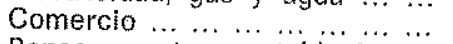 & 35,38 & 30,18 & $\begin{array}{l}33,28 \\
19,06\end{array}$ & - & $\begin{array}{l}94,75 \\
49,70\end{array}$ \\
\hline 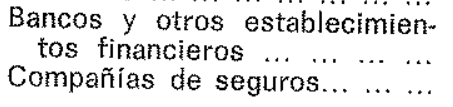 & 95,11 & - & $\underline{35,52}$ & - & $\begin{array}{r}118,99 \\
88,74\end{array}$ \\
\hline
\end{tabular}

Podemos comprobar en estas tablas cómo el sueldo del varón es siempre notablemente superior al de la mujer de la misma rama productiva y calificación profesional, cómo sobrepasa en algunos casos («peones, fabricación de productos de caucho») en más de un 100 por 100 al de la mujer.

He ahí, pues, una discriminación, la salarial, que persiste en nuestro país y que sería preciso eliminar. Y esto tanto si la mujer trabaja por necesidad, como por otros motivos. 


\section{OTRAS PREMISAS DE NO DISCRIMINACION}

Pero la igualdad laboral del hombre y de la mujer no se refiere solamente a las remuneraciones económicas. Porque el que la mujer sea verdaderamente libre para incorporarse al trabajo fuera de casa en igualdad de condiciones con el varón exige, al menos, el cumplimiento de dos condiciones. La primera, que las relaciones laborales se acomoden a su naturaleza femenina. La segunda, que su trabajo sea compatible, de algún modo, con sus funciones de ama de casa y de madre de familia.

En cuanto a la primera, están muy lejos, en los paises industriales en general, gracias a Dios, aquellos cuadros de las novelas de Dickens: mujeres trabajando duramente y larguísimas jornadas en las galerías mineras del carbón. Ha avanzado la legislación y la realidad sociológica en este dominio, aunque no falten lamentables y numerosas excepciones, aun en los paises desarrollados.

Respecto de la legislación internacional, podríamos enumerar, por ejemplo, los siguientes Convenios y Recomendaciones de la O.I.T.: Convenio núm. 45, adoptado en la XIX Conferencia Internacional del Trabajo, de 1935 , relativo al Empleo de las Mujeres en los trabajos subterráneos de toda clase de minas; Convenio núm. 89, de 1948, sobre el Trabajo nocturno de las Mujeres empleadas en la Industria; Convenio núm. 100, de 1951, relativo a la Igualdad de Remuneración entre la Mano de Obra masculina y femenina por un Trabajo de igual Valor; Convenio núm. 103, relativo a la Protección de la Maternidad, aprobado en 1952; Convenio núm. 111, sobre Discriminación en materia de Empleo y Ocupación, aprobado en 1958; Recomendación número 4, aprobada en 1919, sobre la Protección de las Mujeres y de los Niños contra el saturnismo; Recomendación núm. 13, adoptada en 1921, sobre el Trabajo nocturno de las Mujeres en la Agricultura; Recomendación núm. 26, sobre la Protección de las Mujeres y Muchachas emigrantes a bordo de los buques, aprobada en 1926.

En la legislación española: a) La Ley prohíbe el trabajo nocturno de la mujer desde las 21 a las 5 horas (desde las 22 a las 5 horas en la industria textil). b) Como norma general, la jornada de las mujeres, incluidas las horas extraordinarias, no puede ser superior a diez horas. Y esas horas "extra" se han de cobrar con un recargo mínimo del 50 por 100. c) El casamiento puede interrumpir pero no anular el contrato laboral. d) En caso de embarazo, la trabajadora tiene derecho a periodos de descanso y recuperación determinados por la ley. e) El parto da derecho a disponer de tiempos adecuados para la lactancia o a pasar a excedencia voluntaria durante un mínimo de un año 
y un máximo de tres. f) Se reglamenta la seguridad e higiene del trabajo de la mujer, atendiendo a su feminidad. g) $\AA$ las mujeres menores de veintiún años les está prohibido los trabajos que lo están para todos los menores de diecíocho años $y$, además, otros de transporte, arrastre, etc., que exigen la aplicación de notables fuerzas musculares.

En este punto, pues, y en el plano legislativo, España está a la altura normal de cualquier otro desarrollado. Sólo es necesaria la actitud vigilante para que las leyes se cumplan.

La segunda condición para la igualdad de oportunidades con el varón en la vida económicamente activa, decíamos era la compatibilidad de esta última con su rol de ama de casa y de madre de familia. No siempre es fácil y muchas veces imposible, atender a la vez a la casa y a la empresa. Pero hay medios que pueden facilitar la armonía. Entre ellos daremos los que enumera en "Revista Internacional del Trabajo", correspondiente al mes de abril de 1966, Harriet Holter, especialista del Instituto de Investigaciones Sociales de Oslo. Dice: "Cuando se discuten las oportunidades sociales de las mujeres, los temas que más frecuentemente se plantean son: la necesidad de más y mejores instituciones de asistencia a la infancia, oportunidades de empleo a tiempo parcial, incitación de las mujeres a escoger entre más categorías de enseñanza, reeducación y formación profesional, asesoramiento profesional activo y nuevas categorías de empleo abiertas a las mujeres, como, por ejemplo, en la organización de nuevas industrias. También parece necesario un cambio de actitud de los empresarios del sector privado y de las trabajadoras respecto de las oportunidades de ascenso de la mujer, así como una redistribución de las atribuciones domésticas en la familian (13).

\section{LA JORNADA A TIEMPO PARCIAL Y SUS CONDICIONES}

Otro medio que se suele dar es la jornada a tiempo parcial. Pero sucede que la jornada tiempo parcial es aceptada con muchas reservas por los empresarios en general; y esto por las siguientes razones, según un estudio de Alva Myrdal y Viola Klein:

- Aumento de la carga administrativa.

- Costes de la Seguridad Social.

- Dificultades adicionales en la organización de la empresa.

- Sentimiento de no compromiso del obrero o la obrera con la empresa.

(13) Citado por Ramón Bayod Serrat en Diccionario Laboral. Ed. Reus, Sociedad Anónima. Reus, 1969, pág. 359. 
- Recelos de los Sindicatos obreros ante el temor de perder poder negociador en los regateos con la empresa (14).

Son las anteriores, dificultades que vencer, pero que no desvirtúan la validez de la jornada a tiempo parcial para el ama de casa que no pueda abandonar el hogar durante todo el día. Si la jornada a tiempo parcial se pusiera en práctica, no hay duda de que se incorporarian al trabajo fuera del hogar muchísimas más mujeres que al presente. Según una encuesta del INSEE francés entre mujeres que no trabajan, tanto solteras como casadas, las tres cuartas partes no piensan trabajar. Mas, entre las que lo harian, seis de cada diez piensan en un trabajo a tiempo parcial. Con esto se calcula que en Francia podría aumentar la población activa femenina en más de un millón de actuales candidatas a trabajadoras (15).

Escribe, con razón, Noemi Yunes, a propósito de facilitar la alternancia del trabajo en el hogar y en la empresa: "Si la distancia entre el hogar y el lugar de trabajo se redujera, si proliferaran los jardines de infancia, las comidas en las escuelas, los servicios comunitarios-como lavanderías, restaurantes y autoservicios-, si se diera el desarrollo más amplio de la Seguridad Social que permitiera la existencia de mujeres especializadas para ocuparse de llevar un hogar en caso de necesidad, si existiera verdadera camaradería entre el hombre y la mujer para la atención del hogar y la educación de los hijos, la mujer podría asumir con facilidad su nuevo rol en el mundo" (16).

$\mathrm{Y}$ afinando en el mismo tema se han propuesto medidas tales como:

- Permisos legales más largos antes y después del parto.

- Posibilidad de tomar permiso sin sueldo para criar un hijo, con garantía de readmisión y mantenimiento de los derechos.

- Afectación de la mujer encinta a un trabajo que corres. ponda a su situación.

- Permisos excepcionales para cuidar a un hijo enfermo, con indemnización a cargo de la Seguridad Social.

- Retribución de los días de ausencia; hasta cinco días, si ha sido provocada o causada por apremiante necesidad de socorrer al marido o a los hijos.

(14) Cfr. Noemí Yunes Zajur: "El ocio, el trabajo y la mujer", en Revista de la Opinión Pública, núm. 30, págs. 197 y sigs.

(15) Cfr. Congreso Internacional de la Familia, o. c., pág. 67.

(16) O. c., pág. 204. 
Si se avanzara por todos estos caminos, no hay duda de que se iría progresando con rapidez hacia una auténtica liberación laboral de la mujer en igualdad de oportunidades con el varón.

\section{INSTRUCGION E IGUALDAD DE OPORTUNIDADES}

Hay un último aspecto al que quiero también aludir; es el de la instrucción y formación profesional de la mujer. En todas las vertientes de la vida, también la laboral, la instrucción libera. $Y$ se puede comprobar, además, una correlación positiva entre el nivel cultural de la mujer y su incorporación a la vida activa. En los Estados Nnidos, por ejemplo, se ha estudiado esa relación entre los años de instrucción de la mujer y los porcentajes de su incorporación a la vida de trabajo. Los resultados esquemá. ticos son los del cuadro núm. 6 (17).

\section{CUADRO NUM 6}

\begin{tabular}{|c|c|}
\hline $\begin{array}{l}\text { Del total de mujeres con años } \\
\text { de instrucción }\end{array}$ & $\begin{array}{c}\text { Trabajan en la vida } \\
\text { activa }\end{array}$ \\
\hline 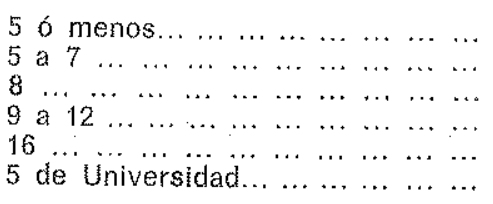 & $\begin{array}{l}18,5 \text { por } 100 \\
28,7 \text { por } 100 \\
31,1 \text { por } 100 \\
38,3 \text { por } 100 \\
44,7 \text { por } 100 \\
72 \text { por } 100\end{array}$ \\
\hline
\end{tabular}

El mismo fenómeno lo confirman estudios paralelos referidos a diferentes países. Por eso, podríamos escribir con el antes citado Harriet Holter: "La política más positiva encaminada a mejorar la participación de la mujer en el trabajo viene proba. blemente aplicándose en la esfera de la enseñanza y de la formación. Estímulo, reeducación y asesoramiento son términos aptos para definir las medidas que ya se han adoptado. Por medio de folletos, conferencias en las escuelas, de charlas radiofónicas y de artículos en el periódico se trata de alentar a las adolescentes a seguir cursos de enseñanza superior o de formación especializada» (18).

Esta instrucción de la mujer no sólo es interesante desde e punto de vista de la economía nacional, puesto que ayuda a movilizar recursos humanos "ociosos", sino también y sobre todo desde el ángulo personal de la mujer, ya que la coloca en un nivel en que su libertad y su igualdad de oportunidades

(17) Cfr. Noemí Yunes Zajur, o. c., pág. 210.

(18) Citado por Pamón Bayod Serrat, o. c, pág. 360. 
J. GOROSQUIETA

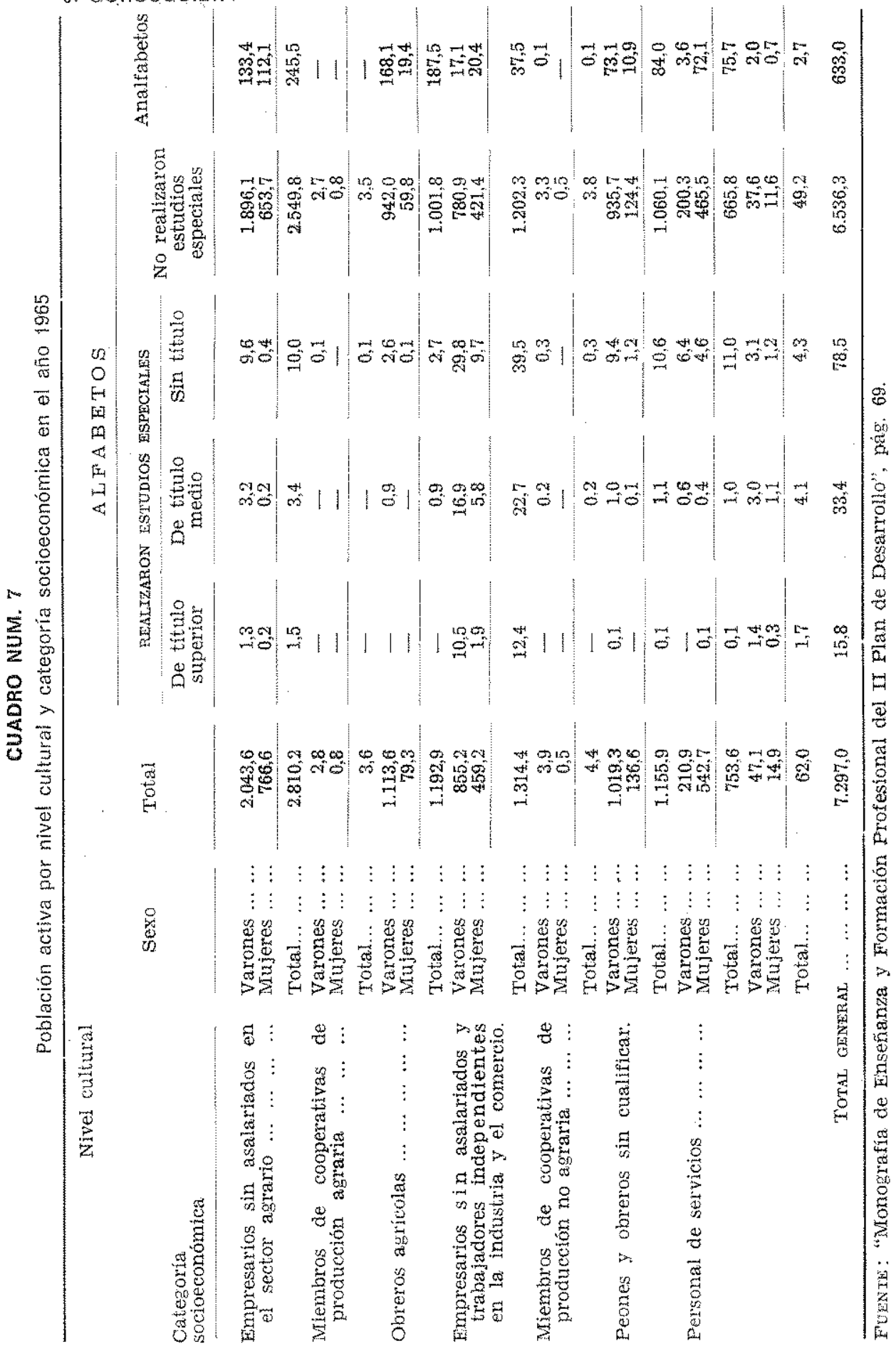


laborales con el varón pueden ser más efectivas. $Y$ en este sentido hay mucho que recorrer, no sólo en España, sino en la generalidad de los países, tanto desarrollados como en vías de desarrollo. Limitándonos al nuestro, remitimos simplemente al lector al cuadro núm. 7. Obsérvese en él cómo, si sacáramos porcentajes, la proporción de trabajadores menos instruidos es mucho mayor entre las mujeres que entre los hombres, sea cual sea el nivel de su respectiva cualificación profesional. Destaquemos algunos casos extremos: a) En 1966 había en España 502.570 varones empresarios $\sin$ asalariados y trabajadores independientes en la industria y el comercio, frente a algo más de la mitad de mujeres $(251.320)$; pues bien, en ese grupo aparece un 36 por 100 más de analfabetos femeninos que masculinos. b) En personal de servicios, por cada varón empleado lo están 2,5 mujeres, mas por cada varón analfabeto del mismo subsector, lo son 14 mujeres.

Lo mismo nos indicarían otras cifras directas de participación de la mujer española en los diferentes escalones del sistema educativo.

\section{CONCLUSION}

Hay mucho, pues, que promover en todos los sentidos. Porque mientras la mujer en general y la española en particular no quede liberada por su incorporación masiva a los sistemas educativos y por la puesta en práctica de los condicionamientos antes apuntados, su igualdad laboral con el hombre será una quimera y existirá siempre el riesgo de que los empresarios la utilicen como verdadero "ejército de reserva industrial" en el sentido marxista de la expresión. 